\title{
Fabrication and Characterization of Aluminium-Rice Husk Ash Composite Prepared by Stir Casting Method
}

\author{
Adnan Adib Ahamed*, Rashed Ahmed, Muhammad Benzir Hossain and Masum Billah \\ Department of Materials and Metallurgical Engineering, Bangladesh University of \\ Engineering and Technology, Dhaka 1000, Bangladesh.
}

*Corresponding author: adnanadib.ahamed99@gmail.com

\begin{abstract}
Metal Matrix Composites (MMCs) constitute an important category of design and weightefficient materials. This article highlights on the work where an attempt is taken to fabricate aluminium matrix composite reinforced with rice husk ash (RHA) particles, an agricultural byproduct with high amount of silica. RHA particles, upon analysis, are incorporated into the $\mathrm{Al}$ matrix melt by stir casting. Magnesium ( 1\%) is used as a wetting agent between matrix and reinforcement. 3, 6 and 9\% wt. of RHA are added into the matrix. The microstructure analysis reveals the reinforcing particle distribution inside the matrix which indicates successful fabrication of the composites. The density and mechanical properties such as strength and hardness are measured for both unreinforced metal and composites. The results found in the tests show a decrease in density with increasing reinforcement while increasing yield strength, ultimate strength and hardness of the composites with increasing reinforcement from the unreinforced condition.
\end{abstract}

Keywords: Metal matrix composites; aluminium; rice husk ash; stir casting; microstructre; mechanical properties.

\section{INTRODUCTION}

Composites are materials made from two or more constituent materials of significant properties, both physical and chemical that, when combined, produce a material with a whole new characteristics better than the individual characteristics of each constituents. These constituents along with the interface determine the characteristics of a composite [1]. However, within the composite the different materials can be identified easily as they do not dissolve or blend into each other. The constituents must be chemically dissimilar and separated by a distinct interface [2]. The most important advantage associated with composites is their high strength and stiffness along with low weight [3]. A typical composite has two parts: a strong, stiff reinforcement, that provides the strength and rigidity which is distributed in a second material, called the matrix, which serves to bind and protect the reinforcements [4]. Composites can be classified as dispersion strengthened, fiber reinforced and particulate reinforced composites based on the reinforcement type and as metal matrix, ceramic matrix and polymer matrix composites based on matrix type [5].

Metal matrix composites (MMCs) are composites where metals or metallic alloys are used as matrix and ceramics or other materials are used as reinforcements. The ductility of the metal matrix with the stiffness and rigidity of the ceramics reinforcements are used which makes MMCs fascinating. The MMCs are lightweight and resist wear and thermal distortion better than their metal counterparts, so it is mainly used in the automobile industry since here the emphasis is reduction and engine efficiency to improve fuel economy [6]. 
Aluminium is popular as a matrix due to its high strength to weight ratio, ductility and malleability, machinability and durability. Rice husk, a low cost and low density material, exhibits superior physical and mechanical properties. Thus RHA can be utilized more effectively in the development of composite materials for various applications [7]. Presence of silica is an additional advantage in comparison to other byproduct materials which makes RHA an important material for a wide range of manufacturing and application oriented processes [8].

MMCs can be processed in either solid state or liquid state methods [9]. Stir casting technique is currently the most common and cost effective commercial method for composite making. Mechanical mixing of the reinforcement particulate into a molten metal bath is the basic principle of this technique. The molten metal matrix is stirred vigorously to form a vortex at the surface of the melt and the reinforcement material is introduced at the side of the vortex. The stirring is continued for a few minutes before the slurry is cast. During stir casting for the synthesis of composites, stirring helps in transferring particles into the liquid metal and maintaining the particles in a state of suspension [10].

In this work, Rice Husk Ash was used as the reinforcement. The main idea was to utilize the agro-industrial waste to reduce its negative environmental impact and at the same time to develop a composite material economically with superior properties.

\section{EXPERIMENTAL}

\section{A. Materials selection}

The matrix material used in this study was commercially pure aluminium of $99.3 \%$ purity and the reinforcement material was rice husk ash prepared from the rice husks collected from Shibganj, Chapainawabganj, Bangladesh. Magnesium at about 1\% of the weight of the matrix was used as the wetting agent for the better adhesion of the reinforcements with the matrix. Mg addition reduces the casting fluidity at the same time it reduces the surface tension of the aluminium [11]. The Mg addition was limited to $1 \%$ as increasing the content above $1 \%$ of the matrix weight increases the viscosity of the slurry to the detriment of particle distribution [12].

\section{$B$. Rice husk ash preparation}

The rice husks were washed thoroughly with water to remove the dusts and dried at room temperature for 24 hours. They were then burnt at open atmosphere to remove the moisture and organic constituents. The color of the husk changed from yellowish to black at this stage due to charring of the organic matter. This was followed by heating the husks at $650^{\circ} \mathrm{C}$ in a heat treatment furnace (Model: SPX Blue M Hi-Treet) for two hours to remove the carbonaceous constituents leaving the grayish which silica rich ash to be used as the reinforcement of the composite. The ash was subjected to chemical analysis by adding drops of $\mathrm{HF}$ acid and heating $0.1 \mathrm{gm}$ of RHA so that the silica content is evaporated as $\mathrm{SiF}_{4}$ and weighing of the residue afterwards determined the percentage of silica content in the ash.

\section{Composite making}

The composite was made by stir casting method. Initially $1.2 \mathrm{~kg}$ of $\mathrm{Al}$ was charged into a graphite crucible and melted to $810^{\circ} \mathrm{C}$ in a pit furnace. As the metal melted, about $15 \mathrm{gm}$ of magnesium was added to the melt as a wetting agent between matrix and reinforcement since it reduces the casting fluidity as well as the surface tension of the molten Al. The 
molten $\mathrm{Al}$ was then transferred to the holding furnace of the stir casting apparatus. RHA particles were preheated to $700^{\circ} \mathrm{C}$ for 1 hour so that the silica content remained amorphous below $800^{\circ} \mathrm{C}$. The graphite stirrer was lowered into the melt and stirring was commenced at 500 rpm to create a vortex. The preheated RHA $(\sim 105-420 \mu \mathrm{m})$ was added slowly into the melt at the side of the vortex to ensure a uniform distribution. The stirring was continued for another 7-8minutes after adding the reinforcement so that the particle distribution and the mixing is done properly. The mixture was poured at a temperature of $732^{\circ} \mathrm{C}$ into a mild steel permanent mold that was preheated earlier to obtain uniform solidification of the casting. In this process 3, 6 and 9\% RHA reinforced $\mathrm{Al}$ matrix composites were prepared.

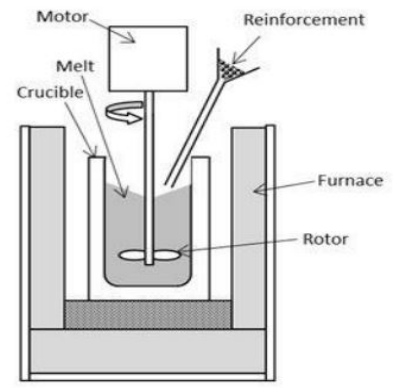

Fig. 1. Schematic diagram of the stir casting apparatus for composite making

\section{RESULTS AND DISCUSSION}

\section{A. Raw material analysis}

$4.5 \mathrm{~kg}$ of rice husk was burnt that produced 948gm of ash as the residue which was approximately $21 \%$ of the rice husk taken initially. The loss of ignition was calculated as $30 \mathrm{gm}$ of ash was heated in the Blue $\mathrm{M}$ furnace for two hours and after the removal of carbonaceous matters, 21.804gm ash content was left. Hence the loss of ignition was (3021.804 ) gm or $8.196 \mathrm{gm}$ or $27.32 \%$. The appearances of the RHA before and after the ignition loss is illustrated in Fig. 2.

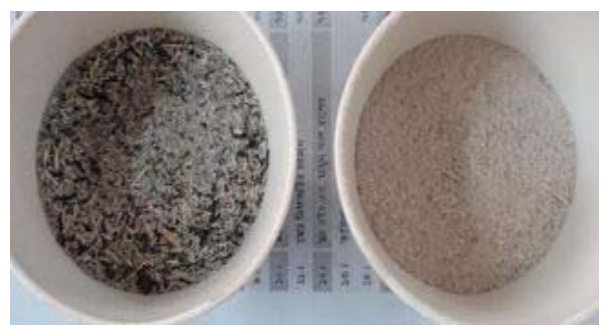

Fig. 2. Rice husk ash before and after ignition 
The ash was the analyzed chemically for silica content and it was found that the RHA contained $90 \%$ silica.

The RHA particles were sieved to observe the particle size distribution and the result of the sieve analysis is presented in Fig. 3. From these particles, the particles within the range of $105-420 \mu \mathrm{m}$ were taken to be used as the reinforcement of the composite.

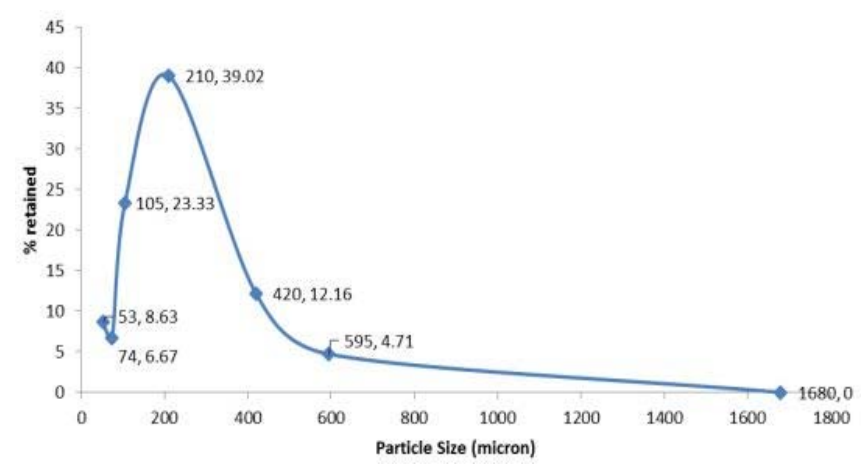

Fig. 3. Particle size analysis of rice husk ash

The aluminium to be used as the matrix was analyzed by means of optical emission spectroscope and the composition was found to be as given in Table 1. From the data obtained it was concluded that the matrix material was commercially pure aluminium.

TABLE I. CHEMICAL COMPOSITION OF ALUMINIUM INGOT

\begin{tabular}{|c|c|c|c|c|c|c|c|c|c|}
\hline $\mathrm{Al}$ & $\mathrm{Si}$ & $\mathrm{Mg}$ & $\mathrm{Mn}$ & $\mathrm{Ni}$ & $\mathrm{Cr}$ & $\mathrm{Ti}$ & $\mathrm{Zn}$ & $\mathrm{Cu}$ & $\mathrm{Sn}$ \\
\hline 99.33 & trace & 0.114 & trace & 0.23 & 0.004 & 0.022 & trace & 0.03 & trace \\
\hline
\end{tabular}

\section{$B$. Microstructural features of the composites}

The variables affecting the distribution of particles are solidification rate, fluidity, type of reinforcement, and the method of incorporation. It is essential to get particles uniformly throughout the casting during particulate composite production. The primary task is to get a uniform particle distribution in the melt and then to prevent agglomeration of particles during pouring and progress of solidification. One of the major requirements for uniform distribution of particles in the melt is its wettability. The wetting of the reinforcement particles by the liquid metal, homogeneous mixing of the melt-particle slurry as well as the particle solidification front interaction determines the final particle distribution and matrix microstructure [13].

The microstructures of the unreinforced matrix and the composites were observed with the scanning electron microscope.

The microstructure of the unreinforced matrix and the reinforced composites are shown in Fig. 4. 
Fabrication and Characterization of Aluminium-Rice Husk Ash Composite Prepared by Stir
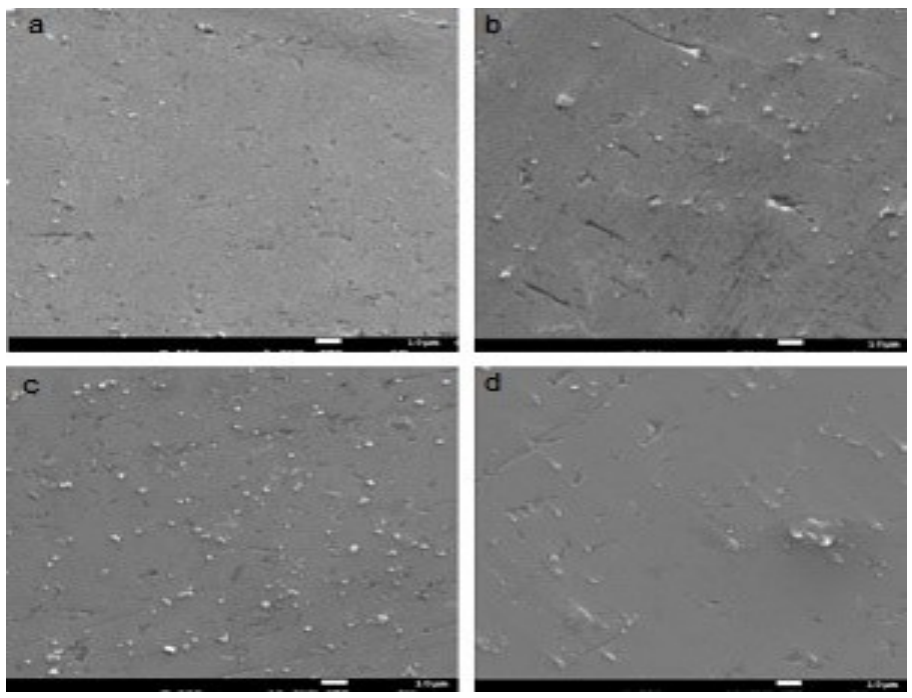

Fig. 4. SEM micrograph of a) pure $\mathrm{Al}, \mathrm{b}) \mathrm{Al}+3 \% \mathrm{RHA}, \mathrm{c}$

$\mathrm{Al}+6 \% \mathrm{RHA}$ and d) $\mathrm{Al}+9 \% \mathrm{RHA}$

From the SEM micrographs it can be seen that RHA particles were well distributed in the matrix for $3 \%$ and $6 \%$ by weight reinforcements but was not as satisfactorily for the $9 \%$ wt. RHA reinforcement. The particles did not retain their original shape due to the vigorous stirring during mixing and during handling prior to mixing. EDS (Energy Dispersive Spectroscopy) analysis was done to ensure that the presence and distribution of the reinforcements within the matrix. The results of the EDS shows consistency with the images from the micrographs. Chemical analysis was performed on each of the $3 \%$, $6 \%$ and $9 \%$ reinforced composite samples. The analysis revealed increasing presence and a good retention of silicon which were due to the addition of RHA which confirmed the new phases in the micrograph to be $\mathrm{SiO}_{2}$ rich RHA as it was apparent from the EDS spectra.

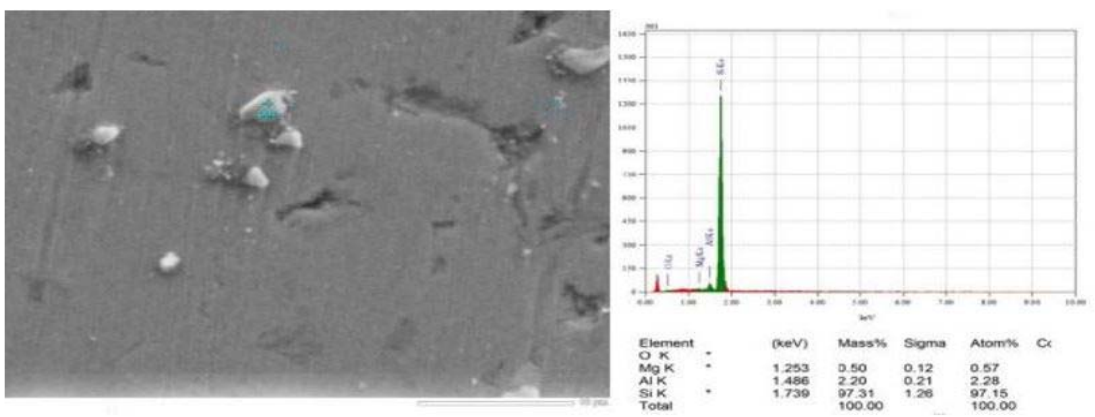

Fig. 5. SEM micrograph and EDS analysis of RHA reinforcement of AL+6\%RHA

\section{Density}

The density was measured by measuring mass of the prepared samples and employing the Archimedean principle by immersing them into a labelled measuring cylinder partially 
filled with water hence calculating the displacement of the water level indicating the volume of the sample. The variation in the apparent densities of the base metal and the reinforced composites are displayed in Fig. 6. It is found that with increasing weight percentage of RHA, the density of the composites decreased. This is due to the fact that amorphous silica that constitutes most of the reinforcement, has much lower density $\left(\sim 2.19 \mathrm{gm} / \mathrm{cm}^{3}\right)$ than aluminium $\left(\sim 2.68 \mathrm{gm} / \mathrm{cm}^{3}\right)$. The drop in density from unreinforced to $3 \%$ RHA reinforced composite was observed to be greater which was attributed by not only the reinforcing particles but also the creation of porosity and voids as a result of vigorous stirring in the open atmosphere. This resulted in some probable air entrapment within the material during solidification. Some porosity were also apparent from the microstructures which arose during casting of the composites. The rate of reduction of the apparent density in the 3\%, 6\% and 9\% RHA reinforced composites were found to be in accordance with the theoretical density reduction calculated to be $2.65 \mathrm{gm} / \mathrm{cm}^{3}$, $2.64 \mathrm{gm} / \mathrm{cm}^{3}$ and $2.62 \mathrm{gm} / \mathrm{cm}^{3}$ respectively as calculated by the rule of mixture in terms of mass fraction of the matrix and reinforcement materials.

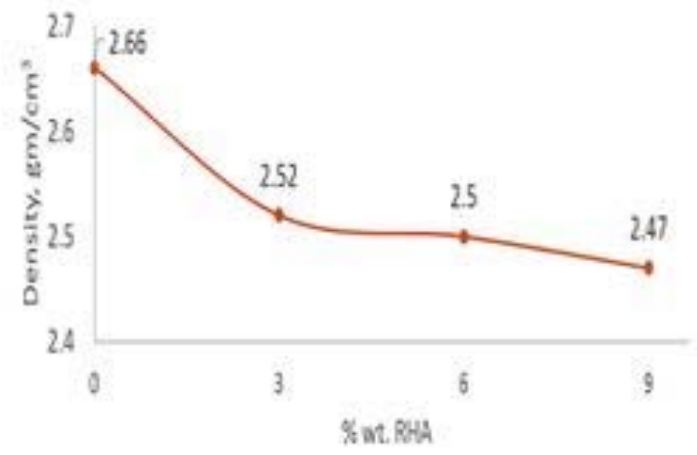

Fig. 6. Density of pure $\mathrm{Al}, \mathrm{Al}+3 \% \mathrm{RHA}, \mathrm{Al}+6 \% \mathrm{RHA}$ and $\mathrm{Al}+9 \% \mathrm{RHA}$

\section{Tensile Strength}

The tensile properties of the composites were measured by preparing tensile samples of pure aluminium and the reinforced composites according to ASTM E8/E8M-09 sub-size standard. The specifications are shown in Fig. 6 and Table 2.

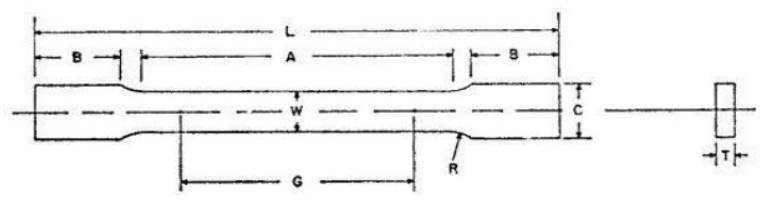

Fig. 7. Schematic diagram of ASTM E8/E8M Subsize tensile sample 
TABLE II. DIMENSIONAL SPECIFICATIONS OF ASTM E8/E8M SUBSIZE TENSILE SAMPLE

\begin{tabular}{|c|c|}
\hline Gage length, $\mathrm{G}$ & 25 \\
\hline Width, $\mathrm{W}$ & 6 \\
\hline Thickness, T & 5 \\
\hline Radius of fillet, $\mathrm{R}$ & 6 \\
\hline Overall length, $\mathrm{L}$ & 100 \\
\hline Length of reduced section, $\mathrm{A}$ & 32 \\
\hline Length of grip section & 30 \\
\hline Width of grip section, $\mathrm{C}$ & 10 \\
\hline
\end{tabular}

The tests were conducted by means of INSTRON Universal Testing Machine.

The variation in the yield strength and ultimate tensile strength from pure aluminium to 3 , 6 and 9\% RHA reinforced composites increased gradually as shown in Fig. 8 and Fig. 9. Both the yield and ultimate tensile strength of the composites increased with increasing amount of reinforcement due to the presence of stiffer RHA particles which produced mismatch in the matrix reinforcement interface to impede the motion of dislocations. The strength of the Al-9\% RHA reinforced composite was the highest but the rate of increase of strength was significantly lesser than the previous composites which was due to nonhomogeneous distribution of the reinforcing particles into the matrix as was apparent from the micrograph. Much of the reinforcing ash was rejected during stirring which was caused as a result of the bonding between the matrix and reinforcement being lessened due to improper wetting of the reinforcements for the absence of an inert atmosphere during stir casting.

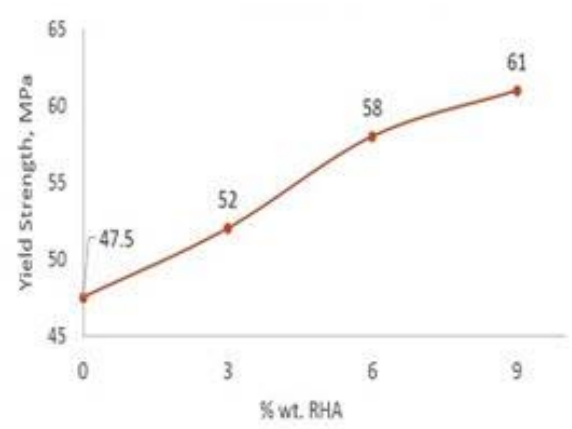

Fig. 8. Yield strength of $\mathrm{Al}, \mathrm{Al}+3 \% \mathrm{RHA}$, $\mathrm{Al}+6 \% \mathrm{RHA}$ and $\mathrm{Al}+9 \% \mathrm{RHA}$

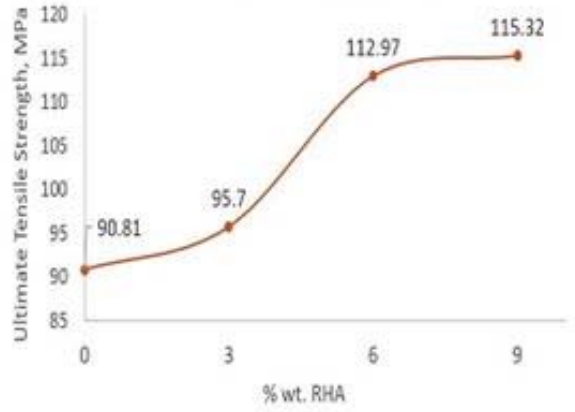

Fig. 9. Ultimate tensile strength $\mathrm{Al}$, $\mathrm{Al}+3 \% \mathrm{RHA}, \mathrm{Al}+6 \% \mathrm{RHA}$ and $\mathrm{Al}+9 \% \mathrm{RHA}$

\section{E. Hardness}

Brinell hardness was measured for the base metal and the composites by means of SHIMADZU UH-500kNA machine. 4.9KN load was applied by using a steel ball of diameter $10 \mathrm{~mm}$.

The hardness of the composites was increased in comparison to the unreinforced $\mathrm{Al}$ and the increase was gradual with increasing percentage of reinforcement. The variation in the Brinell hardness number of the composites is shown in Fig. 10. The reinforcing particles, 
being harder and stiffer than the matrix, resisted the plastic deformation caused by the indenter and contributed to the increasing hardness of the composites with increasing reinforcement percentage.

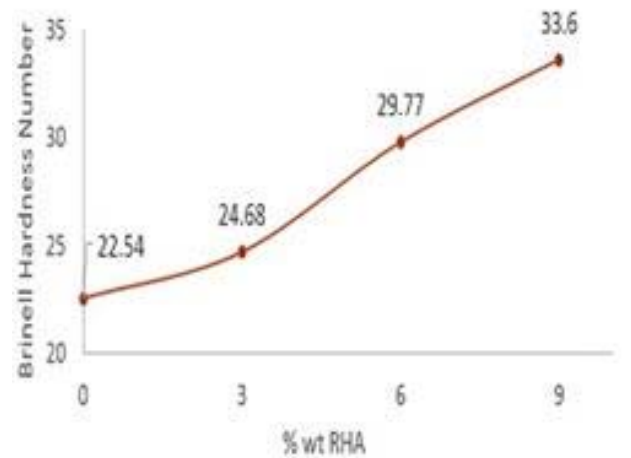

Fig. 10. Brinell hardness of $\mathrm{Al}, \mathrm{Al}+3 \% \mathrm{RHA}, \mathrm{Al}+6 \% \mathrm{RHA}$ and $\mathrm{Al}+9 \% \mathrm{RHA}$

To sum up, the variation in density, yield strength, ultimate tensile strength and hardness from pure $\mathrm{Al}$ to composites with 3\%, 6\% and 9\% RHA reinforcements can be tabulated as in Table 3.

TABLE III. VARIATION IN DENSITY, YIELD STRENGTH, ULTIMATE TENSILE STRENGTH AND BRINELL HARDNESS OF AL, AL+3\%RHA, AL+6\%RHA AND AL+9\%RHA COMPOSITES

\begin{tabular}{|c|c|c|c|c|}
\hline Samples & $\begin{array}{c}\text { Density } \\
\text { (gm/cc) }\end{array}$ & $\begin{array}{c}\text { Yield strength } \\
\text { (MPa) }\end{array}$ & $\begin{array}{c}\text { Ultimate } \\
\text { tensile strength } \\
\text { (MPa) }\end{array}$ & $\begin{array}{c}\text { Brinell } \\
\text { hardness } \\
\text { (BHN) }\end{array}$ \\
\hline $\mathrm{Al}$ & 2.66 & 47.5 & 90.81 & 22.54 \\
\hline $\mathrm{Al}+3 \% \mathrm{RHA}$ & 2.52 & 52 & 95.7 & 24.68 \\
\hline $\mathrm{Al}+6 \% \mathrm{RHA}$ & 2.50 & 58 & 112.97 & 29.77 \\
\hline $\mathrm{Al}+9 \% \mathrm{RHA}$ & 2.47 & 61 & 115.32 & 33.6 \\
\hline
\end{tabular}

The results found show that the yield strength, ultimate tensile strength and hardness of the composites increased gradually with increasing amount of RHA reinforcement into the matrix while decreasing the density. These are in consistency with different research on the utilization of RHA particles in Al alloy matrix.

A study investigating the effects of 2, 4, 6 and 8\% wt. RHA particulate reinforcement in A356.2 alloy produced by stir casting technique showing the reduction in density from about $2.7 \mathrm{gm} / \mathrm{cm} 3$ to $2.55 \mathrm{gm} / \mathrm{cm} 3$ while increasing the hardness from around 65 to 82 BHN [14].

The trends in the rate of increase in tensile strength, hardness and the rate of decrease in density was similar in the case of AlSi10Mg alloy reinforced with up to $12 \%$ RHA particles and this study showed that the rate of increasing the tensile strength dropped when the percentage of reinforcement was increased to around $9 \%$ and then the tensile 
strength began to reduce with further increasing the amount of reinforcement [15], a similar tendency to which is observed in the current work as well.

Up to $15 \%$ RHA was incorporated in Al2.8Si0.8Fe alloy to obtain increased tensile strength (115MPa-126MPa) and hardness (55BHN-80BHN) while decreasing density $(2.8 \mathrm{gm} / \mathrm{cm} 3-2.6 \mathrm{gm} / \mathrm{cm} 3)$ with a similar trend found in the current work, the higher percentage of RHA retention being due to the employment of double stir casting [16].

An attempt to make a hybrid composite of $\mathrm{Al}$ (6061) alloy, RHA and $\mathrm{Cu}$ by stir casting technique retained RHA particles up to $32 \%$ by weight of matrix material with $3 \% \mathrm{Cu}$ and the hardness of the composites were measured to increase with increasing reinforcement concentration [17].

Thus although the strengths and hardness for the $\mathrm{Al}$ alloy matrix composites were greater compared to the metallic Al matrix composites prepared in the current work, the rate of change of the properties with increasing RHA reinforcement has been in consistency with the rate observed in the current work. RHA particles contributed in improving the physical and mechanical properties of the pure metallic aluminium in a similar manner as in different $\mathrm{Al}$ alloys. The properties, in particular the rate of increase of strength and hardness as well as the rate of decrease of density from $\mathrm{Al}+6 \% \mathrm{RHA}$ to $\mathrm{Al}+9 \% \mathrm{RHA}$ can be improved to some extent by incorporating an inert or closed system during stir casting by insulating the setup from the atmosphere. This would reduce the contact of the melt with the air to reduce oxidation and air entrapment to remove porosity to give a better control over the process and hence obtain better set of properties.

\section{CONCLUSIONS}

From the work it can be concluded that RHA can be successfully incorporated into pure aluminium matrix for the production of composites. This can also solve the problem of storage and disposal of RHA and utilization of an agricultural waste. Addition of up to 9\% by weight RHA to aluminium was done by stir casting route to produce composites. Addition of magnesium improved the wettability of RHA with aluminium melt and thus increased the retention of the RHA in the composite. Hardness of the composites is increased from 22BHN to $33 \mathrm{BHN}$ with addition of RHA and magnesium compared to unreinforced condition. The Ultimate tensile strength and the yield strength has improved with increase in RHA content while decreasing the density ensuring the potential application of materials with lighter weight but superior strength.

\section{Acknowledgment}

The authors would like to acknowledge the support of Department of Materials and Metallurgical Engineering, Bangladesh University of Engineering and Technology, Dhaka, Bangladesh for the experimental supports.

\section{References}

[1] Meyers $\mathrm{M}$ and Chawla K, "Mechanical behavior of materials $2^{\text {nd }}$ ed.," Cambridge University Press, pp. 765, 2009.

[2] Callister WD, "Materials science and engineering: an introduction $7^{\text {th }}$ ed," John Wiley and Sons Inc., pp. 144-148, 2007.

[3] “Engineered materials handbook: composites,” ASM International, Materials Park, Ohio, USA, vol. 1, 1989. 
[4] Lin KY, “Composite materials: materials, manufacturing, analysis, design and repair,” William E. Boeing Department of Aeronautics and Astronautics, University of Washington, pp. 1-4, 2014.

[5] Askeland DR, Fulay PP and Wright WJ, "The science and engineering of materials $6^{\text {th }}$ ed," Cengage Learning Inc., pp. 653-684, 2010.

[6] Keshavamurthy R, Prabhu V, Pai S, Kumar V and Vinay HN, "Development and characterization of industrial waste reinforced metal matrix composite," Dayananda Sagar College of Engineering, Bangalore, India, Project Ref No. 37S0401.

[7] Kumar A, Mohanta K, Kumar D and Prakash OM, "Properties and industrial applications of rice husk ash: a review," International Journal of Emerging Technology and Advanced Engineering, vol. 2(10), pp. 86-90, 2012.

[8] Adebisi AA, Maleque MA and Rahman MM, "Metal matrix composite brake rotor: historical development and product life cycle analysis," International Journal of Advanced Mechanical Engineering, vol. 4, pp. 471-480, 2011.

[9] Jha NK, Dvivedi A, Rajendra S and Srivastava UK, "Development processes of cost effective aluminium metal matrix composites- a review,” International Journal of Advanced Mechanical Engineering, vol. 4, pp. 389-394, 2014.

[10] Hull D and Clyne TW, “An introduction to composite materials,” Cambride University Press, 1996.

[11] Korolkov AM, "Casting properties of metals and alloys," Consultant Bureau, New York, USA, pp. 26-37, 1963.

[12] Hashim J, Looney L and Hashmi SJ, "Metal matrix composites: production by the stir casting method,” Journal of Materials Processing Technology, vol. $92-93$ (30), pp. 1-7, 1999.

[13] Uyyuru RK, Surappa MK and Brausthaug S, "Tribological behavior of Al-Si-SiCp composites/automobile brake pad system under dry sliding conditions,” Tribol. Int. vol. 40, pp. 365-373, 2007.

[14] Prasad S and Krishna AR, "Fabrication and characterization of A356.2-rice husk ash composite using stir casting technique,” International Journal of Engineering Science and Technology, vol. 2(12), pp. 7603-7608, 2010.

[15] Saravanan SD and Kumar MS, "Effect of mechanical properties on rice husk ash reinforced aluminium alloy (AlSi10Mg) matrix composites,” International Conference on Design and Manufacturing, Procedia Engineering, vol. 64, pp. 1505-1513, 2013.

[16] Aigbodin VS, "Development of A;-Si-Fe/rice husk ash particulate composites synthesis by double stir casting method," USAK University Journal of Material Science, vol. 2, pp. 187197, 2012.

[17] Mittal A and Muni R, "Fabrication and characterization of Al-RHA-Cu hybrid metal matrix composites,” International Journal of Current Engineering and Technology, vol. 3(5), pp. 1779-1783, 2013. 